\title{
The Walnut Industry Development Strategies Based on the Perspective of Precise Poverty Alleviation in Danfeng County
}

\author{
Shiqing Yan \\ College of Urban and Planning, Yancheng Teachers University, Yancheng, China \\ Email: 18360494968@163.com
}

How to cite this paper: Yan, S. Q. (2017). The Walnut Industry Development Strategies Based on the Perspective of Precise Poverty Alleviation in Danfeng County. Advances in Applied Sociology, 7, 391-403. https://doi.org/10.4236/aasoci.2017.712026

Received: November 27, 2017

Accepted: December 24, 2017

Published: December 27, 2017

Copyright $\odot 2017$ by author and Scientific Research Publishing Inc. This work is licensed under the Creative Commons Attribution International License (CC BY 4.0).

http://creativecommons.org/licenses/by/4.0/

\section{(c) (i) Open Access}

\begin{abstract}
In order to give full play to the role of regional characteristic industries in poverty alleviation work of China, it is necessary to explore the development strategies of regional characteristic industries under the background of precise poverty alleviation. This article analyses the number of poor people, the labors of poverty, the structure, employment status and spatial distribution characteristics of labor in poverty in the county. According to the characteristics of the poor population and its labor force, this article presents the development strategies of the walnut planting and processing, walnut and its products circulation, walnut culture tourism and walnut industry research and development, based on the perspective of industry precision poverty alleviation.
\end{abstract}

\section{Keywords}

Precise Poverty Alleviation, Characteristics of Poor Population, Labor Force Situation of Poverty, Industrial Characteristics, Walnut Industry, Development Strategy

\section{Introduction}

Eliminating poverty, improving people's livelihood and gradually realizing common prosperity are the essential requirements of the socialism (Wang, 2016; Zhuang et al., 2016; He, 2017). Since the reform and opening up, China's governments at all levels have focused on poverty alleviation and poverty shaking off. And the poverty alleviation policy has shifted and there are different forms, such as reform to promote poverty alleviation, rural development poverty alleviation and development and protection combination poverty alleviation. In recent years, China pursues all-round precision poverty alleviation; in addition to 
targeting all the poor population, the precise principle runs through the whole process of poverty alleviation (Luo \& Yi, 2011; Ma \& Kai, 2017; Gong \& Gong, 2017; Huang, 2016; Tan \& Lin, 2017). Different from the foreign countries taking payments to support the poor, China adopts the strategy of multiple paths in poverty alleviation and the development of production poverty alleviation as the main path after aiming at the poor population (Zhang et al., 2015), and industry poverty alleviation has become the most important way to precision poverty alleviation (Huang et al., 2017).

At the same time, the academic circles summarize the rich experience of precise poverty alleviation in the areas of mountain (Ma, 2016; Li, 2017; Sun, 2016), ethnic minority areas (Liu et al., 2017; Yu, 2016; Yang, 2016; Yu, 2016), concentrated contiguous poverty-stricken areas (Yang, 2016), and other different types of areas in the country, and study the plight and solution measures of precision poverty alleviation in specific industries in specific areas (Huang et al., 2017; Ma, 2016; Yang, 2016). They studied in the theoretical orientation (Liu \& Zhan, 2016), function mechanism (Chen, 2016), path selection (Sun, 2016; Chen, 2016), implementation method (Li, 2013), policy simulation (Chen, 2016), policy evolution (Wang, Li, \& Zuo, 2016), policy differentiation and other aspects of the industry precise poverty alleviation, and put forward a series of unique insights (Yu, 2016), and discussed the relationship between the environmental protection and industry precision poverty alleviation (Han, Sun, \& Pu, 2009), supply side structural reform and precision poverty alleviation (Kong, Zheng, \& Liu, 2017), the application of big data in industry precision poverty alleviation (Zheng \& Cao, 2015), and other aspects of the precise poverty alleviation. The research of the specific industries in poverty alleviation has been done, such as the important role of industrious in the precise poverty alleviation (Wang \& Yu, 2017), characteristic industries in the precise poverty alleviation (Zhang \& Dou, 2017), the relationships in characteristic industry (Geng, 2017) and the coupling relationship between financial services and characteristic industry in the precise poverty alleviation.

The above research has made a positive contribution to industrial precision poverty alleviation. However, in the background of precise poverty alleviation, how to develop the regional characteristic industry to give full play to the poverty alleviation effect deserves further study. Based on the analysis of poverty characteristics in Danfeng County, this paper discusses the development strategies of walnut industry in the county, in order to enrich the theory of characteristic industry precise poverty alleviation and guide the practice of precise poverty alleviation.

\section{The Characteristics of Poverty in Danfeng County}

Danfeng County located in the eastern section of the Qinling Mountains in southeastern Shaanxi province, which is a national poverty-stricken county. The spatial distribution and employment status of the poverty-stricken population in the county is an important basis for formulating the industry precise poverty al- 
leviation strategy.

\subsection{The Number Characteristics of the Poor}

The current poverty line of China is based on 2300 yuan of an annual per capita income of residents at the constant price of 2010 as benchmark. According to the changes of the price level, China's poverty line was 3000 yuan in 2016 (Xinhua Reporter, 2017). Based on this standard, there were 61,244 people in Danfeng county, making up 19.65 percent of the total population of 311,722 , this year. The number of poor people in each town and its proportion of the total population is different. In terms of the number of poor people, the number of people living in poverty in each town is between 3008 and 13,299. Among them, the number of poor people in the street of Longjuzhai is the most, reaching 13299. The town of Zhulinguan was second with 7149 people. The number of poor people in the town of Huapingzi is the lowest, with a total of 3008 people. From the proportion of the total population of the poor, the proportion of the total population of poverty-stricken people in the whole county is 19.65 percent, and the proportion of poverty-stricken people in the streets of each town is $14.00 \%$ to 32.46 . Among them, the proportion of poor people in the town of Huapingzi is the highest in the total population, reaching $32.64 \%$. The poverty-stricken people in the street of Longjuzhai have the lowest proportion of the total population, about $14 \%$. In the 12 towns (streets) of the county, the population of the poor is less than the average of the whole county and only the Longjuzhai streets and Shang towns (see Table 1).

\subsection{The Labor Structure of the Poor}

According to the ability of labor, the poor people can be divided into three categories: the poor with the ability of labor and the poor people who are not working age, etc. From the county scope, the poverty of the poor in Danfeng county has reached 39,599, accounting for 64.66 of the entire poor population. The number of poor people who have lost their working capacity is 1811 , accounting for $2.96 \%$ of the total poverty. The number of people living in poverty in the non-working age was 19,834, accounting for 32.39 of the poor.

In the composition of the working poor population, the proportion of ordinary labor force is up to $99.51 \%$ and the number reaches 39,405 . The proportion of skilled labor was 0.49 percent, with 194 people in total (see Table 1).

\subsection{The Employment Status of the Poor}

The labor force in poverty employment has important effects on precision poverty reduction strategy. From the point of employment, in 2016 the Danfeng county's poor labor employment for 16,736 people, accounting for $42.26 \%$ of the total labor force in poverty. The numbers of employment people outside the province, in the province outside the county, in the county outside the town and in the town are 1588, 5664, 3452 and 6032 respectively (see Table 2).

From the time of employment, the labor force of the poor people in Danfeng 
Table 1. Population and poverty of each town (street) in Danfeng County in 2016.

\begin{tabular}{|c|c|c|c|c|c|c|c|c|}
\hline & \multirow{2}{*}{$\begin{array}{l}\text { Population } \\
\text { Of the county }\end{array}$} & \multicolumn{2}{|c|}{ Impoverished people } & \multicolumn{3}{|c|}{ The labor force in poverty } & \multirow{2}{*}{$\begin{array}{c}\text { Poor who } \\
\text { lost their } \\
\text { working ability }\end{array}$} & \multirow{2}{*}{$\begin{array}{l}\text { No-working } \\
\text { age in poverty }\end{array}$} \\
\hline & & Amount & Percent & Amount & $\begin{array}{l}\text { Skilled } \\
\text { labors }\end{array}$ & $\begin{array}{c}\text { Ordinary } \\
\text { labors }\end{array}$ & & \\
\hline Longjuzhai Street & 94,959 & 13,299 & 14.00 & 8556 & 49 & 8507 & 317 & 4426 \\
\hline Yuling town & 17,127 & 3607 & 21.06 & 2112 & 16 & 2096 & 418 & 1077 \\
\hline Caichuan town & 13,871 & 3358 & 24.21 & 2049 & 10 & 2039 & 141 & 1168 \\
\hline Luanzhuang town & 22,626 & 4907 & 21.69 & 3322 & 10 & 3312 & 83 & 1502 \\
\hline Tieyupu town & 17,077 & 3640 & 21.32 & 2441 & 3 & 2438 & 29 & 1170 \\
\hline Wuguan town & 21,406 & 5099 & 23.82 & 3148 & 10 & 3138 & 170 & 1781 \\
\hline Zhulinguan town & 32,887 & 7149 & 21.74 & 5276 & 29 & 5247 & 105 & 1768 \\
\hline Tumen town & 12,311 & 2670 & 21.69 & 1705 & 3 & 1702 & 94 & 871 \\
\hline Siping town & 16,903 & 4825 & 28.55 & 2940 & 4 & 2936 & 89 & 1796 \\
\hline Shang town & 30,407 & 5121 & 16.84 & 3151 & 35 & 3116 & 193 & 1777 \\
\hline Lihua town & 22,933 & 4561 & 19.89 & 2803 & 22 & 2781 & 63 & 1695 \\
\hline Huapingzi town & 9215 & 3008 & 32.64 & 2096 & 3 & 2093 & 109 & 803 \\
\hline whole county & 311,722 & 61,244 & 19.65 & 39,599 & 194 & 39,405 & 1811 & 19,834 \\
\hline
\end{tabular}

Data source: poverty statistics of Danfeng County (internal data), Danfeng County Poverty Alleviation Bureau, December 2016.

Table 2. Labor employment situation of poor people in Danfeng county in 2016.

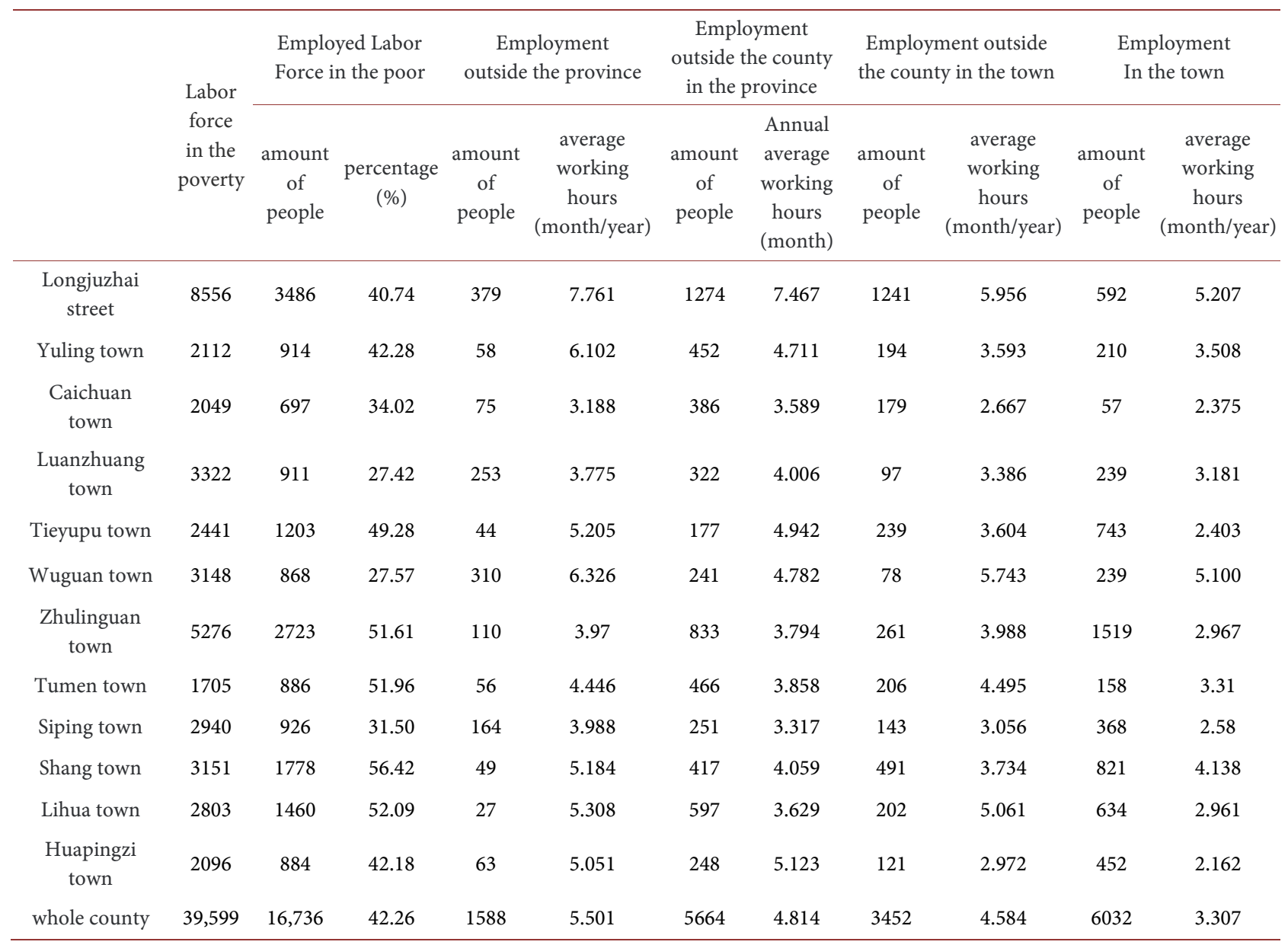

Data source: poverty statistics of Danfeng County (internal data), Danfeng County Poverty Alleviation Bureau, December 2016. 
County in 2016 can be divided into four types: work outside the province, work in the province outside the county, work in the county outside the town and in the town. Among them, the average annual working time is 5.501 months, 4.814 months, 4.584 months and 3.307 months respectively (see Table 2).

\section{The Role of Walnut Industry in Presice Poverty Alleviation in Danfeng}

Industrial poverty alleviation is one of the important ways to alleviate poverty. The development prospect of walnut industry and the competitive advantage of walnut in Danfeng County make the industry play an important role in the precise poverty alleviation in Danfeng County.

\subsection{The Walnut Industry in Danfeng County Has a Promising Prospect}

Walnut contain many kinds of nutritious ingredients beneficial to human body, which are good for human health (Li et al., 2009; Yang et al., 2017). The demand for walnuts in international markets is growing fast. According to the latest statistics from the UN food and agriculture organization, the total trade volume of walnut and walnut meat in the world was 551,367 tons and 350,355 tons respectively in 2013. Trade volume increased by 2.71 times and 1.97 times compared with 2003. The United Nations food and agriculture organization predicts that the annual growth rate of international walnut demand will remain above 10 percent for the next 10 years.

Asian and Chinese walnut imports are rising fast. In 2013, the import volume of raw walnut in Asia reached 158,680 tons, accounting for $62.64 \%$ of the world's total import volume, and the net import volume was 118,642 tons. In the decade from 2003 to 2013, the amount of walnut imports in Asia increased by 23.2 times, with annual growth of $36.94 \%$. China (including Hong Kong and Taiwan) is the country with the largest import volume of walnut in Asia. In 2013, the import volume of raw walnut in China reached 64,454 tons, accounting for 40.62 percent of the total Asian imports, far surpassing the total of 49,113 tons in Vietnam. China was the fastest growing number of walnuts in Asia. In the decade between 2003 and 2013, the amount of Chinese walnut imports increased by 99.3 times and the annual growth rate reached $58.38 \%$. Imports are well over 14.7 times that of Vietnam, the second largest in Asia.

With the improvement of people's living standard and health care consciousness enhancement, walnut products in the international market demand and volume increased year by year, a huge number of population product consumption and demand for walnuts in China will grow rapidly and walnut industry has great development prospects.

\subsection{The Walnut Industry in Danfeng County Has Obvious Competitive Advantage}

Planting history and planting preferences. Danfeng County is known as the 
walnut capital of China. The walnut cultivation in Danfeng County can be traced back to the han dynasty. It was the first place in China that successfully introduced the walnut. The book in qianlong period of the qing dynasty named Zhili Shangzhou wrote: the most delicious food in Shangluo state is the walnut. There are 1900 walnut trees in wuguan township of danfeng County, with an annual output of 2000 kilograms, before liberation in 1949. After the founding of new China, the planting of walnuts was more common, and its planting experience has been promoted to the whole country many times.

Walnut regional brand. In 1958, chairman MAO Ze-dong introduced the experience to the whole country, and the experience was to grow an acre of walnuts per acre in Shangluo district. In the same year, chairman MAO Ze-dong held a production of walnut production at Bayi Forest Farm in Wuguan Town, Danfeng County, and awarded the state council certificate signed by premier Zhou En-lai to Bayi Forest Farm in Wuguan Town. In 2008, danfeng walnuts became a national geographic brand, and wuguan walnuts gained national geographic sign registration protection. Chairman MAO's call and premier zhou's signing of the award, for the danfengxian county walnut regional brand to add luster. The establishment of the protection brand of geographical indications makes the chicken walnut truly become the important agricultural product regional brand in China.

Location advantage. Dan-feng County is located in the south of the eastern section of Qin-ling Mountains, and the elevation is between 500 and $1200 \mathrm{~m}$. The terrain is dominated by the valley and mountainous terrain, and the mountain peaks are separated and undulating. Because of the barrier of the Qin-ling Mountains, the climate is mild, the winter is not very cold, the summer is not very hot, the rain is abundant, the four seasons are clear, it is the natural ideal growth place of walnut. China is a big importer of walnuts. In recent years, more than 64,000 tons of raw walnut and walnut meat have been imported from abroad, and the demand and imports are still growing at a high speed. In this context, the location advantage of the walnut industry is very obvious. First, compared with the pecan producing areas, the location advantage of the walnuts has been converted into cost advantage. Dan-feng County is located in the eastern part of the Qin-ling Mountains, and the Shang-yu Ancient Road through the county. The G312 National Highway and the Xihe Railway Line runs diagonally across the county, providing convenient transportation for walnut products to be shipped to the country. Second, compared with the domestic walnut producing region, the development of the walnut industry has obvious scale advantages. All over the Shang-luo District includes Dan-feng County is a brand of walnuts, with good quality and high yield. With an annual production capacity of 20,000 tons, walnut production ranks first in the national prefecture-level cities. The scale advantages effect of Dan-feng walnut was obviously, the development potential of walnut industry is huge, which is in competition with walnut products in other parts of the country. Third, the related industries of the Dan-feng wal- 
nut industry are well matched, which can effectively reduce the cost of sales. There is rich tourism resource in Danfeng County, which can form a coordinated development between the tourism industry and the walnut industry.

\subsection{The Walnut Industry in Danfeng County Can Absorb More Labor Force}

At present, the walnut industry is mainly labor-intensive industry, and the development of walnut industry can absorb more labor force. In walnut planting, the mountainous terrain and broken block is small, so the walnut field of digging, Weeding fertilization, pest fruit picking, etc. to mechanical work, must be manually operated, so more labor cost. The pruning of walnut branch needs certain experience, also must manual work, need to spend more labor force. Walnut pretreating, bigger and complete walnuts the highest prices, the price of the first-class is often twice of the seconds. Therefore, walnuts are usually used in the processing of walnut food by manual shell, can absorb more common labor. Similarly, the transport of walnuts and its products, as well as the production of walnut food and walnut oil, also absorbs more general labor.

\subsection{The Walnut Industry in Danfeng County Can Increase the Farmers Income}

Investigation shows, the walnut yield of Danfeng County between 3000 - 4500 $\mathrm{kg} / \mathrm{hm}^{2}$, the walnut purchase price for $10-15 \mathrm{yuan} / \mathrm{kg}$, the cost of fertilize about 3000 yuan $/ \mathrm{hm}^{2} \cdot \mathrm{a}$, and the cost of pesticide about $600 \mathrm{yuan} / \mathrm{hm}^{2} \cdot \mathrm{a}$, the land transfer costs 12,000 yuan $/ \mathrm{hm}^{2} \cdot$ a. In normal years, the walnut purchase price was 10 yuan $/ \mathrm{kg}$ with the walnut yield $3000 \mathrm{~kg} / \mathrm{hm}^{2}$, and the profit is $14,400 \mathrm{yuan} / \mathrm{hm}^{2} \cdot \mathrm{a}$. According to the local terrain conditions and mechanization level, a labor force usually can grow 0.75 hectares of walnuts. Under the background of land transfer, the annual income of a labor force planted walnut can reach 10,800 yuan, which can drive 3 people out of poverty. The development of walnut industry can bring some profit for farmers. The walnut hand shelling as an example, a farmer can peel walnut 15 kilograms every day, if the according to 2 yuan $/ \mathrm{kg}$, each labor can earn 900 yuan a month. If the time can be arranged scientifically, each labor works 3 months a year, and can earn 2700 yuan per year. If we consider the walnut deep processing and walnut industry to promote the development of tourism and increase farmers' employment opportunities and increase farmers' income, the effect of increasing farmers' income of walnut industry development will be more obvious.

\section{The Development Strategies of Walnut Industry in Danfeng County}

According to the situation of Danfeng County, proposed the strategies of walnut planting and processing, walnut products circulation, walnut cultural tourism and the related research and development of walnut industry. Through establishing the core area of national geographical indication walnut protection 
demonstration area, the walnut deep processing and walnut cultural tourism demonstration area, the northwest Chinese walnut products distribution center and the walnut research and development center of Shan-xi province to promote the development of walnut industry and give full play to the role of walnut industry in precise poverty alleviation.

\subsection{Walnut Planting Development Strategy}

Enlarge the planting area of walnut. The main layout is along the three sections of Wu Guan River Basin, Yin-hua River and "312 National Road" which are the appropriate sections of walnut cultivation. Taking the hundred acres of walnut forest belt along 312 State Road, Danjing Road, Dansi Road, Danyu Road, Danluan Road and Wuzhao Road and other five walnut roads and the Zhulinguan town, Tumen town, Yuling town, Luanzhuang town and other 10 shallow townships' walnut ditches as key areas, and gradually increasing the proportion of walnut forest in sustainable growing area of walnut.

Scale management, change the variety of structure. Taking the existing walnut gardens as the main object, establishing several new walnut picking gardens; carrying out walnut seedlings graft transformation, developing high-quality walnut varieties; constructing standardized demonstration bases and pollution-free demonstration bases. Deal with the relationship between the appearance of walnut trees and landscape and fruit picking around tourist attractions and along the tourist routes to coordinate the relationship between walnut cultivation and ecotourism.

Innovating the business model. Taking the business model of "company + cooperatives + farmers", building the beneficial supply and marketing relations in the form of contract of walnut processing enterprises, walnut planting cooperatives and walnut growers. This will not only solve the problem of the shortage of funds for poor population developing of the walnut crop, but also provide a steady supply of raw materials for the walnut processing enterprises.

In the background of industry precise poverty alleviation, the selection of walnut varieties and pruning methods mainly consider their yield in the common walnut garden, but in the picking experience walnut park mainly consider the landscape and convenient picking, along both sides of the road the choice walnut varieties and pruning method consider the usage of walnut tree in landscape making and the shading effect.

\subsection{Walnut Processing Industry Development Strategy}

First, establish a number of walnut processing enterprises. In the model of "company + cooperative + farmer", establishing a number of primary processing enterprises such as peeling, drying and husking in specialized walnut planting villages to absorb the local labor force. This is not only to promote the walnut industry develop, but also help solve the employment of the labor in poverty and help them get out of poverty. In the large population and more labor area, such as Longjuzhai district, Shang town, Wuguan town, Zhulinguan town and other 
towns, set up walnut further processing enterprises, using walnut to process jujube walnut, amber walnut, walnut candy and other snack foods; using walnut kernel to process walnut oil, walnut dew and other food oils and beverages; using walnut shell to product activated carbon and activated carbon handicraft; using the septum in walnut to product health tea; using walnut green husk to product dyes and lubricants.

Second, introduce and cultivate walnut industry leading enterprises. Take investment promotion outside the county, the county consolidation and recombination and other measures to foster supporting 2 to 3 leading enterprises in the walnut industry. Developing walnut oil, walnut dew and other walnut food actively, using walnut shell, walnut green skin and so on to develop the deep processing products, and from 1 to 2 processing output or sales of more than 100 million yuan of walnut processing business leading enterprises. At present, efforts should be made to increase capital attraction to support the existing walnut shell of scientific and technological companies' project of development and utilization of the walnut shell to be put into effect; speed up the docking with Walnut Beverage Co., Ltd; accelerate the pace of the introduction of walnut oil manufacturing enterprises; introduce walnut membrane development and utilization projects as soon as possible.

Third, encourage hotel hotels to develop walnuts diet. Supporting a number of guesthouses and hotels in the county and important tourist attractions to launch walnut diet with regional characteristics and making the walnut cuisine become one of the important attractions that attract tourists gradually. Coordinating the development between walnut industry and tourism and promoting the poverty-stricken population to get out of poverty.

\subsection{Walnut Product Circulation Industry Development Strategy}

First, establish Northwest China walnut trading center. Establish Northwest China Walnut Trading Center near G312 exit in Longju Village or Industrial Concentration Area in Shang town. On the one hand, this layout can use the convenient of G312 highway, South West Railway and other transport lines to help transport goods; on the other hand, this can take location advantage of Danfeng in the Shangluo region to carry out all the cross-county large transactions of Danfeng County walnut products in the trading center and strive to attract around half the volume of transactions around the border counties. The main mode of operation is the original wholesale walnut and walnut products, and to carry out a nationwide variety of walnut trading business.

Second, establish walnut regional sales market. According to the spatial characteristics of local industries, traffic conditions, topography and residential distribution, establishing a regional walnut sales market in Zhulinguan Town, Wuguan Town and Luanzhuang Town with the original purchase of original walnuts, and facilitating the sales and circulation of peasants' original walnuts.

Third, establish a number of walnut products sales electricity supplier. The 
government can support the development of e-commerce for the sales of walnut products in the form of financial support, technical services and the establishment of the online exhibition hall of Danfeng walnut and expand the sales channels of original walnut and walnut products.

Fourth, improve the visibility of Danfeng walnut brand. Promoting the brand identity of Danfeng walnut geographical indications through the news media; intensifying the advertising efforts of walnut products in the Pearl River Delta, Yangtze River Delta, Bohai Rim, economically developed provinces, metropolitan cities and mega-cities; relying on the propaganda effect of tourism and Visitors' personal experience and making the good quality of Danfeng walnut products be perceived by more consumers.

\subsection{Walnut Cultural Tourism Industry Development Strategy}

Strengthen walnut planting related research and development and establish relevant research institutions Taking Wuguan town walnut cultural tourism resources as the basis, and walnut tourism industry. First, develop walnut culture resources. Developing the Wuguan town "Bayi forest farm" national walnut production site monument, the certificate Premier Zhou personally filling in and Wu Guan walnut geographical indications brand and other tourism resources deeply. Second, hold the Walnut Cultural Tourism Festival for visitors to experience picking walnut and the production of walnut products and so on. Carrying out a combination of development with the Shang-luo Area and the surrounding counties and cities, taking the initiative to docking Shangluo walnut open bar festival and other activities, using characteristics in Danfeng to develop differently and form resultant force. Third, making cultural tourism attractions and other types of tourist attractions in series and carrying out the combination of development.

\subsection{Walnut Cultivation and Walnut Products Research and Development Strategy}

Strengthen walnut planting related research and development. With universities, scientific research institutions to establish cooperative relations, the establishment of walnut seedlings, in place of grafting, pest control, R \& D institutions of walnut products processing. Accelerate the introduction of new varieties and new technology research and extension, deepening the cultivation technique of grafting technique, study on landscape design of technology and management technology. Establish related research institutions

Establishing relations of cooperation with the Chinese Academy of Agricultural Sciences, Northwest Agriculture and Forestry University and the relevant scientific research institutes in Shaanxi Province and Shangluo area gradually, founding walnut cultivation and walnut product research and development sub-center in Danfeng County. Establishing a walnut nursery, grafting, pest control, walnut product processing and other researches and development insti- 
tutions in Longjuzhai street. Speed up the introduction of new varieties and the research and popularization of new technologies, deepening the grafting techniques, optimizing the cultivation techniques, standardizing the management techniques and improving the processing techniques under the guidance of provincial and regional business departments.

Establishing walnut dishes research center, learning from walnut chicken pot, walnut fried chicken, walnut bean paste, walnut shrimp and other different dishes of R \& D experience. Introduce a regional food culture with walnut diet constantly with the help of the specialties of the region in Danfeng, Shangluo, Shannan, and even Shanxi.

\section{Conclusions}

The analysis of Danfeng County walnut industry development strategies under the background of precise poverty alleviation has an important inspiration for the industrial precise poverty alleviation of poverty-stricken area.

Firstly, the regional walnut industry has good development prospects. The strong competitiveness and environment effects can absorb much labors, which will play an extremely important role in precise poverty alleviation. In actual work, it is necessary to discriminate the different industries and carry out in-depth research and scientific planning for the industries that meet the above conditions, so as to give full play to its role in the precise poverty alleviation. In addition to the walnut industry, other industries with the above conditions should be also in-depth study and scientific planning in the industry precise poverty alleviation in Danfeng County.

Second, in order to give full play to the positive role of regional characteristic industries in precise poverty alleviation, regional characteristic industries planning must consider all of the economic benefits, ecological benefits and social benefits of it. The difference of the select rules of the walnut varieties and pruning methods among the common walnut gardens, walnut picking experience parks and the walnut landscape forests in Danfeng County is to give full play to the positive role of the industry in precision poverty alleviation.

Third, in order to maximize the comprehensive benefits of regional characteristic industries in precision poverty alleviation, we should not only take into account the regional natural conditions, economic characteristics and social conditions, but also take full account of the characteristics of the poor population and the characteristics of the labor in poverty. The walnut processing enterprises address selection in Danfeng County considered the characteristics of the poor people and the distribution and employment status of the labor in poverty and other factors.

\section{Acknowledgements}

This research is supported by the project of philosophy and social science research in colleges and universities in Jiangsu province (No. 2016SJB840022). 


\section{References}

Chen, X. A. (2016). Study on Interactive Development of Ecological Environment Protection and Industry Precision Poverty Alleviation in Qinba Mountain Area. Gansu Social Sciences, 6, 184-190.

Chen, X. Y. (2016). Predicament and Countermeasures of Industry Precise Poverty Alleviation in Mountain Area. Rural Economics, 5, 87-90.

Geng, X. (2017). Research on the Differential Policy of Targeted Poverty Alleviation: To Support the Development of Minorities with Less Population as an Example. China Agricultural University Journal of Social Sciences Edition, 5, 33-41.

Gong, P. H., \& Gong, P. M. (2017). On the Practice and Theory of Socialist Poverty Alleviation with Chinese Characteristics. Shanghai Journal of Economics, 9, 10-17.

Han, J. L., Sun, R. M., \& Pu, H. Y. (2009). Thirty Years of China's Rural Poverty Alleviation Policy Reform from the Perspective of Social Development. Guizhou Social Sciences, 2, 67-76.

He, P. (2017). Research on the Rule of Law in the Implementation of the Strategy of Targeted Poverty Reduction in China. Law Science Magazine, 1, 50-58.

Huang, C. W. (2016). Research on China's Path of Development-Oriented Poverty Reduction: Review and Prospect. China Agricultural University Journal of Social Sciences Edition, 5, 5-17.

Huang, C. W., Zou, Y., \& Liu, J. (2017). Industry Precision Poverty Alleviation: Practical Difficulties and Deepening Ppath. Guizhou Social Sciences, 9, 125-131.

Kong, L. Y., Zheng, T., \& Liu, Z. (2017). Practical Difficulties and Reasons Interpretation of Precision Poverty Alleviation Project in Concentrated Ethnic Poverty Stricken Area. Issues in Agricultural Economy, 10, 35-43.

Li, M., Liu, Y., \& Sun, C. (2009). Research Progress on the Walnut Nutritional Value. Journal of the Chinese Cereals and Oils Association, 6, 166-170.

Li, X. Y. (2013). Methodology of How China's Poverty Alleviation Progects Implement. Social Sciences in Guizhou, 7, 101-106.

Li, Z. P. (2017). Capital Transfer or Cash Transfer: Path Analysis of Chinese Industry Precision Poverty Alleviation and its Policy Simulation. Journal of Finance and Economics, 4, 68-81.

Liu, B. H., \& Zhan, L. (2016). Problems and Countermeasures of Poverty Alleviation through Agricultural Industrialization. Chinese Journal of Agricultural Resources and Regional Planning, 3, 1-5.

Liu, J. S., Chen, X., \& Cao, J. H. (2016). The Mechanism of the Industrialization of Precise Poverty Alleviation. China Population, Resources and Environment, 6, 127-135.

Luo, Z., \& Yi, Y. L. (2011). Empirical Analysis of Poverty Alleviation Effect of Economic Growth in Western Underdeveloped Areas. Journal of Southwest Minzu University (Humanities and Social Science), 10, 88-92.

Ma, F., \& Kai, Y. (2017). Policy Shifts about China’s Rural Poverty Alleviation Development and Its Challenges: Based on Example of Mabian Yi Autonomous County. Journal of Northwest A\&F University (Social Science Edition), 6, 1-8.

Ma, N. (2016). Research on Precise Poverty Alleviation of Characteristic Industries in Ethnic Areas: A Case Study of Chinese Herbal Medicine Development Industry. Journal of South-Central University for Nationalities (Humanities and Social Sciences), 1, 128-132.

Sun, G. (2016). On Coupling Mode of Financial Service in Ethnic Regions and 
Well-Targeted Poverty Alleviation of Feature Industry. Journal of Northwest University for Nationalities (Philosophy and Social Science), 3, 154-159.

Tan, X., \& Lin, J. (2017). Deepening Research on the Practice of Xi Jin-ping's Thought of Poverty Alleviation. Chinese Rural Economy, 9, 2-16.

Wang, B., \& Yu, F. (2017). Path Selection of Precise Poverty Alleviation in Mountainous Areas Based on Green Development Concept. Rural Economy, 10, 74-79.

Wang, R. (2016). Precision Poverty Alleviation: New Model, New Strategy and New Measures for Poverty Alleviation and Shaking off Poverty in China. Contemporary China History Studies, 1, 82-85.

Wang, Y., Li, B., \& Zuo, T. (2016). Theoretical Orientation and Practical Logic of Precision Poverty Alleviation: Based on the Perspective of Fine Society Theory. Guizhou Social Sciences, 5, 156-161.

Xinhua Reporter (2017). Twelve Million and Four Hundred Thousand Poor People in Rural Have Been Out of Poverty in China in 2016. People's Daily Overseas Edition, 3, 1.

Yang, W. (2016). Analysis of Precision Poverty Alleviation from the perspective of Ecological Niche. Guizhou Social Sciences, 8, 155-160.

Yang, X., Wu, B., Luo, Y. et al. (2017). Analysis of the Pb Accumulation Characteristics and the Health Risk Assessment in Walnut. Biomass Chemical Engineering, 3, 48-54.

$\mathrm{Yu}, \mathrm{X}$. (2016). Characteristic Industry Poverty Alleviation Focuses on "Precision". Administration Reform, 4, 25-28.

Yu, X. (2016). Dealing with the Six Relations of Industry Precision Poverty Alleviation. Chinese Cadres Tribune, 6, 95.

Zhang, M., \& Dou, S. (2017). Study on Mechanism of Agricultural Supply Side Reform and Precision Poverty Alleviation. Journal of Northwest A\&F University (Social Science Edition), 6, 18-24.

Zhang, T., Chen, G., \& Lan, H. (2015). A Study to Subject's Behavior Logic and the Action Mechanism in Accurate Poverty Alleviation. Guangxi Ethnics Studies, 6, 138-146.

Zheng, R., \& Cao, G. (2015). Research on Precise Poverty Alleviation Mechanism Based on Big Data Thinking. Guizhou Social Sciences, 8, 163-168.

Zhuang, T., Yang, F., \& Zeng, W. (2016). The Connotation of Precise Poverty Alleviation and the Dialectical Relationship between Shaking off Poverty and Targeted Poverty Alleviation. Inner Mongolia Social Science, 3, 6-12. (In Chinese) 